\title{
Economic House for the Developing Countries
}

\author{
Mohamed Abdalla Almherigh, \\ Ph.D., M. Eng., B.Sc. Eng. Department of civil EngineeringFaculty of Engineering - Tripoli University P O Box \\ 82677, Tripoli, Libya
}

\begin{abstract}
Building houses are no longer a primary need. In the $21^{\text {th }}$ century, they have developed into an art of self-expression and definition. The barriers of traditional housing have been replaced by creativity and cultural subjectivity. But despite the increasing development, economic consideration was never left behind.

However, the term 'economic' does not really define as 'small' anymore, but rather 'efficient'. Designs that incorporate energy efficient considerations are increasing especially in rural and arid areas. We discover that desert areas contain many possibilities of increased house efficiency, but common desert design has seemed to neglect them. There are several methods of producing and preserving independent energy for daily requirements that we suggest.

Synopsis: This paper contains the discussion of providing economic houses for arid and desert areas, especially Middle East. It provides several analysis of existing desert houses and provides suggestion for efficiency purposes.

The second section is a literature review on how to build an economic house. The suggestion is general and the basic of economic architectural considerations. The next part explains the research method we are using within this paper. Then, we display a modern design of desert houses and shortly comment on the design. We also incorporated the discussion of more traditional houses in desert areas which are called the Courtyard house. In the final section, we conclude the previous discussions and provide several suggestions to increase efficiency.

Keywords: economic house, desert house, rural house
\end{abstract}

\section{Executive Summary}

The term economic is not always define as small or cheap, on the other hand, it describes the effort of providing efficient ways to build and maintaining houses. Several ways of making sure that efficiency efforts are maximized are by preparing sufficient financial planning, using alternative materials, taking advantage of existing space efficiently, and designing the house to be energy efficient.

Financial planning can be done by cooperation with local builders, observing existing houses in similar environment with similar designs and being diligent and careful for small details that have significant cost influences. There are several designs of desert houses. We divide them into traditional and modern houses. Because our topic of discussion is efficiency, we are focus more on the modern design and giving suggestion to the design for efficiency efforts. We elaborate the traditional desert house design shortly in the discussion section and in the next section we present suggestion on both designs.

\section{Statement Of The Problem}

Shelter is mankind's primary needs. Providing for a comfortable and satisfactory housing is an essential part of human's life and cannot be separated from culture and civilization itself. Today however, people see houses as more than just shelter and primary survival needs, we also se it as representation of personality, whether it is individual or collective personality. Modern designers today are more likely to work using local culture as basic inspiration of their work rather than adapting existing and famous designs. Style determination and classification has become more and more subjective as new and unique houses are built according to local needs rather than standard designs (Greenspun, 2004).

Problems however, rose when local culture demanded highly specified house designs due to unique economical and environmental circumstances. For example, in the developing countries, housing budgets are obviously much lower than modern countries. Some of them would have to use alternative materials, make the best use of available spaces, and design energy efficient houses for local needs. Environmental issues could have also pose as a significant influence to house designs. For example, a house built in the desert or arid areas would require different designs and perhaps present different possibilities of alternative energy sources compare to humid areas. Within this paper, we will address the problem mentioned above by elaborating simple suggestions for designing economic houses for desert areas. 


\section{Literature Review}

The discussion of building an economic house started when the first house is build. People are always trying to find cheaper ways to obtain their comfortable houses. But in developing countries, it is obvious that these economical needs are relatively more intense than modern countries like Europe and the United States. There are several perspectives of building an economic house. The term 'economic' can be define as taking proper financial planning in building a new house, using alternative materials rather than common expensive ones, taking advantage of existing land-space to the optimum use and building an energy efficient house or houses which have their own alternative energy sources. Within this literature review, we will not define economic houses as small houses, but houses which construction and maintenance cost equal to the benefits gained. We will take part in the discussion, using the perspectives mentioned above. We will also relate the discussion to the specific object of study, which is to build economic houses in the Middle East, which consist of arid lands and desserts.

\section{II.1TAKING PROPER FINANTIAL PLANING}

If we have a detailed blueprints of the house we are about to built, than any professional builder would be able to tell us how much will it cost. However, it is better for us to make a proper 'estimation' prior to producing our own blueprint. There are several ways of accurately estimating how much a house would cost in unfamiliar areas:

\section{COOERATING WITH LOCAL BUILDERS}

Literature or local information can provide us with the prices of specific materials, but the danger of miscalculating due to accidentally excluding some of the important material or steps of construction would still be significant if we are building in foreign areas. Thus the appropriate effort is to contact local builders with experience in building similar constructions. After understanding the idea of our design, the builder will display alternative of materials and the accurate estimation of building cost (Katuin, 2005).

\section{USE SQUARE MTER}

In unfamiliar areas, one of the easiest ways to predict the cost of a house is by looking at the price of houses with similar style, style and quality in the environment, deducted with the cost of land and divides them with total square meter of the house. After obtaining the average cost of several houses in the environment, we should have a proper estimation of the environment's cost of house per meter (Katuin, 2005).

\section{SPECIAL FEATURES}

The most expensive parts of the house are usually bathrooms and kitchens. Special details like windows, vaulted ceilings and high roof pitches would increase the cost of a house. Certain shapes and different sites require different costing also. In calculating the cost of a house per footage, we must carefully incorporate detailed factors that could make significant difference. Make sure that our sample houses are built in similar conditions (Katuin, 2005).

\section{INFLATION AND MARKET CONDITION}

Inflation is often neglected in cost calculation. In construction projects that take years of building, local price-related issues like inflation and distribution problems could disrupt the building process in foreign areas (Katuin, 2005).

Regarding rural houses, there are particular issues needed to be paid attention to. Local facilities, site selection, access, energy availability, communication and safety are a few aspects needed more attention for rural houses. To shorten the discussion, we will provide 20 important aspects of building a rural house according to Cork County Rural Design Guide, which are local facilities; prominence; energy; sun; shelter; access; power; water; telecoms; drainage; fuel/storage; refuse; work area; recycling; TV/satellite (if necessary); parking; privacy, safety; clothes line; garden/amenity ('The Right Design', 2004). However, some of these consideration aspects might be eliminated for economic purposes.

\section{II.2 USING ALTERNATIVE, LOCAL OR NATURAL RESOURCES}

There are several choices of alternative building materials. For the loft, we can choose to use cellulose, flax, hemp, sheep wool, wood wool or wood fibre. We could use cellulose, cork, flax, hemp, sheep wool, wood wool and wood fibre for wall options also. These materials are entirely organic, renewable, and reusable and have low embodied energy which implies cheaper prices. But other choices like using rock wool, fibreglass or vermiculate are also available, but despite being reusable, the later materials are inorganic, non-renewable and have high embodied energy, thus implies slightly higher prices (Sustainable Housing, n.d). 


\section{II.3 ENERGY MANAGMENT}

In reality, every house owners wants to save money from construction or bills. However, many of them have not realized that many of those efforts can be done in the planning stage of a house ('Energywise', 2005). There are several ways to produce savings from cutting house expenses. Using less energy to heat or cool the house is a good place to start. This condition can be achieved using solar and or wind energy together with appropriate insulation systems. The fact is, we need to combine many site selection, the right design and appropriate materials selection to create an energy efficient home. For examples, concrete floors can store or emit warmth or cool temperature; window placing would also give significant affect to the house's temperature (Energywise, 2005). Solar or wind energies are renewable everlasting and environmentally clean, and can be used either as the main source or as a backup to fusel fuel energy available from public network.

\section{Methodology}

There are two kinds of research method, quantitative and qualitative. Qualitative is a research method designed to generalized certain conclusions toward a limited area of research. This limited area of research, or what we know as population is not generally all taken for consideration. Samples are chosen to represent the entire population under the study. The researcher proposed one or more hypotheses and then concluded whether the samples taken for the study comply with the hypotheses or not. The determination requires justification from sufficient and appropriate mathematical or statistical measurements. The result will then be generalized over the entire population.

Quantitative, on the other hand, does not emphasize on generalization of the population. It presented the research to understand the unique nature of sample under the study. The researcher states the subject of research and then chooses an object for research. It goes deeper than quantitative method to analyze significant aspects and factors that might not been considered in the study of different objects. These aspects are then elaborated to describe the object of study based on the criteria elaborated in the determination of the subject. Comparisons are sometimes conducted for differentiation purposes, but generalizations are not required, thus statistical justifications are not mandatory.

Due to the nature of this study we are using the qualitative method to describe how houses in Middle East are built and how we can contribute by providing suggestions in the sense of economical efficiency. Within common circumstances, actual field study is required for deeper understanding of the object, but relating to resources available, we are taking advantage of existing information about the subject and the object of study trough literatures, journals, and internet articles. In short, the elaborations and conclusions on this journal are based on passive observations and literature reviews.

\section{Statistical Analysis}

This is an example of a relatively large desert house design: First Floor (212 sq.m)

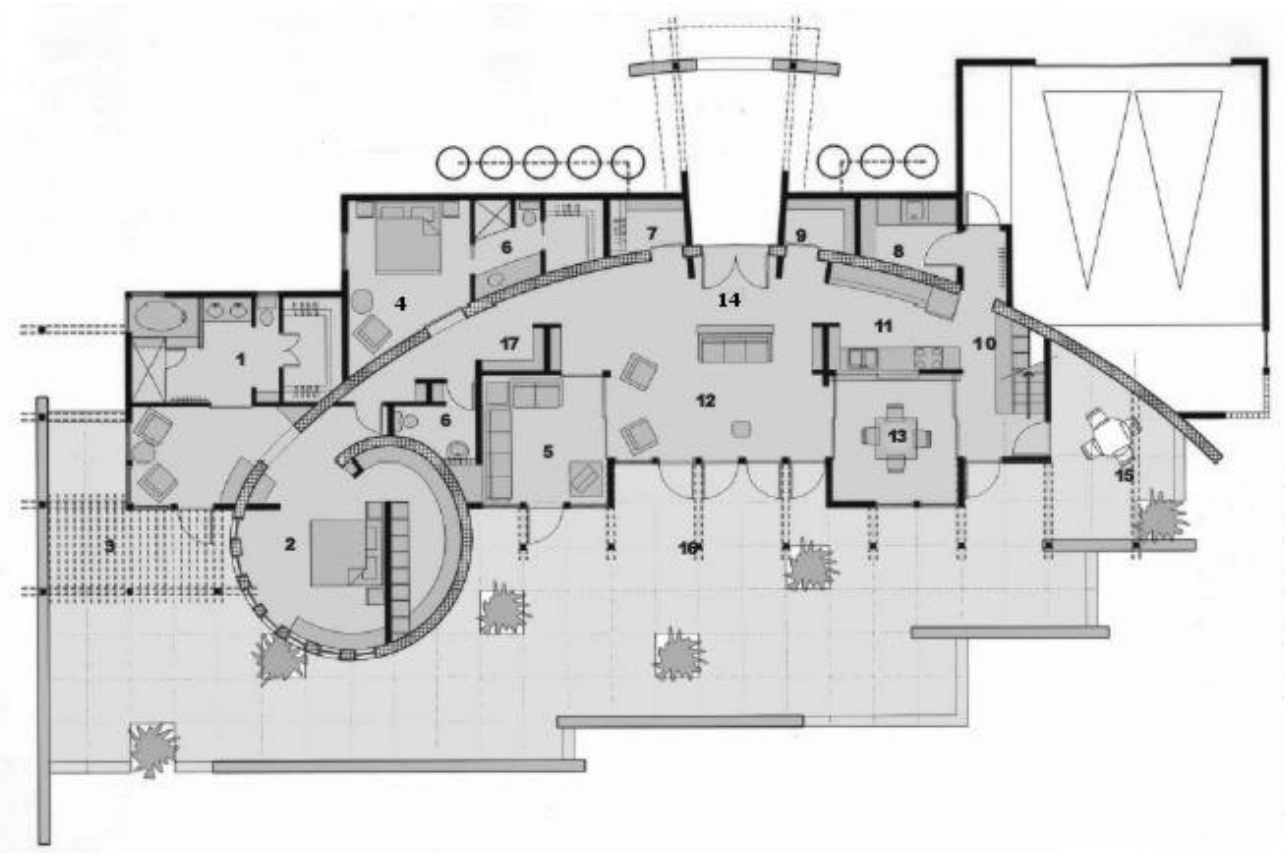

Figure I 
First Floor

Available at http://www.dreamgreenhomes.com/plans/desertorganic.htm Key to Figure I:

1.) Master bathroom 2) Master bedroom 3) Master patio 4) bedroom/guest/den 5) Multifunctional room 6) Bathroom 7) Storage 8) Laundry 9) Pantry 10) Hallway. 11) Kitchen. 12) Living area. 13) Dining area. 14) Entry. 15) Outside dining area. 16) Outside living area 17) Library/circulation (Prudden, n.d).

Second Floor (74 sq m)

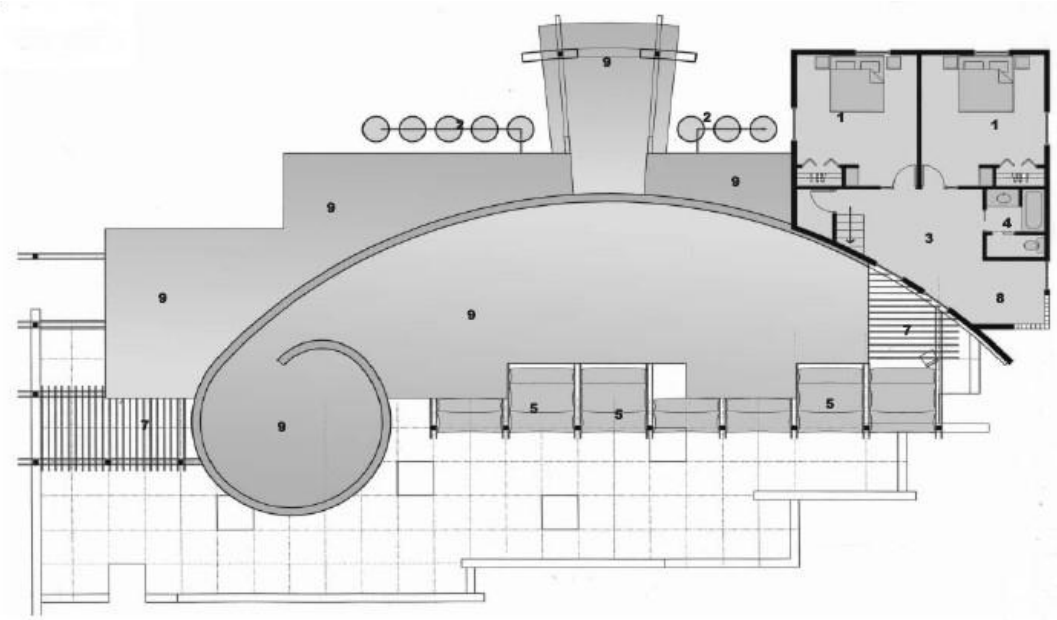

Figure II

Second Floor

Available at http://www.dreamgreenhomes.com/plans/desertorganic.htm

Key to Figure II

1) Bedroom 2) Rain water storage 3) Loft 4) Bathroom 5) Canvas awnings (for summer shading) 6) Rain water storage 7) Shade trellis 8) Play area 9) Rain water collection (Prudden, n.d).

Cross Section and Passive Solar Design

Figure III

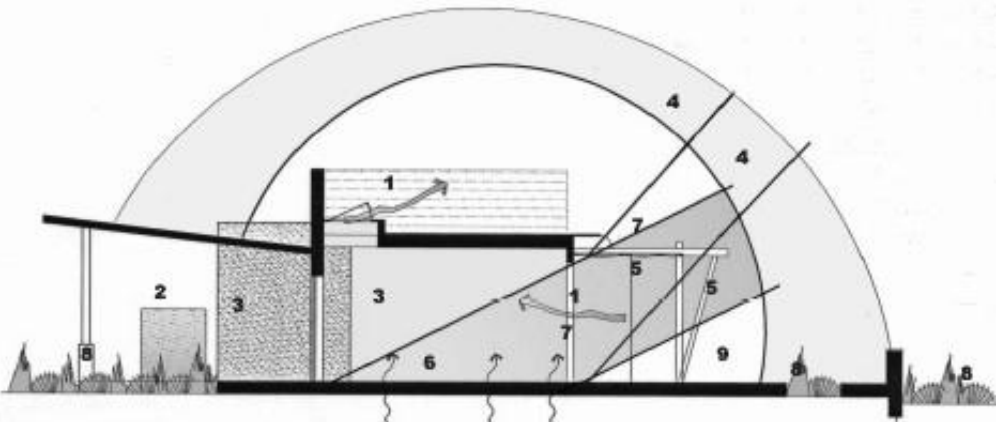

Passive Solar Energy Design

Available at http://www.dreamgreenhomes.com/plans/desertorganic.htm

1) Natural ventilation (cooling trough convection) 2) Rain water storage 3) Rain water collection 4) Summer sun shading 5) Winter sun access (sun is allowed to heat the home) 6) Concrete walls and floors. 7) Retractable awning. 8) Natural landscape 9) outdoor living (Prudden, n.d)

Figure IV 
Visual

Available at http://www.dreamgreenhomes.com/plans/desertorganic.htm

This house presented a design for a family. The original design, which mostly uses concrete as building materials, would require a large amount of money relating to its large size and designs.

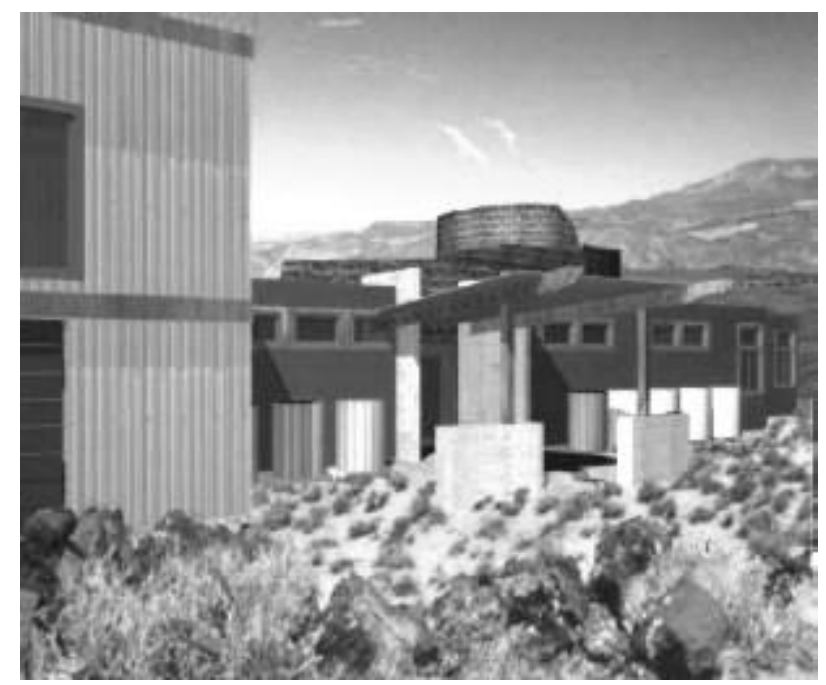

\section{Results}

The house displayed above have already described a viable design of energy efficient house. It has advantages of vertical and horizontal house expansion possibilities. Passive design for heating and cooling and the design of living spaces, assures comfort for every member of the family.

However, the use of alternative materials for the construction is preferable to reduce cost. It is better if design incorporates sustainable materials for their recycled content, recyclables and manufacturing process. The materials for construction should also be stable materials, to ensure healthy indoor environment. We are also suggesting various alternative of energy saving efforts that are specially designed for desert houses. The efforts incorporate water efficiency efforts and efforts to reduce energy consumption within the house.

\section{Discussion}

There are other and more traditional house designs in the Middle East. As we have mentioned before, culture plays a significant role on house designs. The environmental condition of the Middle East logically provide room for inhabitants to expand their house horizontally, however cultural values sometimes produces different facts.

The Moslems for examples, created the courtyard house which consist of four different levels, ground and entry floor, upper floor, roof terraces and basement. The ground floor contained the main spaces in the house, living room, kitchen and multipurpose room. The central room is used for family interaction, children play areas and for weddings and festivals. The family room was used mainly for family activities or for receiving female guests. The upper floor is used for male guest rooms, bedrooms, storage and multipurpose spaces. This floor was usually connected to the neighbouring house by a wall which provides a socializing facility between female members. The roof terraces contained many spaces for summer family activities like sleeping and sitting at night (Solieman \& Clark, 1989).

From the above elaboration, we can see how culture significantly influences the design of a house. Moslem culture have high places for family relationship, therefore, we witness many spaces are dedicated for family interactions. Moslem culture also demand separation between unrelated women and men, thus, there are two guest rooms, for men and women. There are even specialized room to meet women guests.

\section{Conclusion \& Recommendations}

There are several different designs of houses in the desert. The picture displayed above described desert houses designed by using modern technology in consideration and eliminating some cultural factors. The courtyard house on the other hand describe a more common and traditional house of the desert inhabitants. According to our considerations, the modern house is obviously the more energy efficient design. It is large due to architectural convenience, but it takes more advantage of the desert condition and provides cost savings. However, we have suggestion of how the house could be improved to produce optimum efficiency. Some of this condition could also be used to develop the traditional courtyard houses. 

Outdoor:

There are several strategies of water conservation for desert houses.

1. Low water-use-plants

2. Efficient irrigation systems with seasonal control and moisture sensors

3. $\quad$ Contoured yard, patios and walk ways directing to plants

4. Rooftop rainwater harvesting for direct use by plants or for storage and later irrigation of plants

5. Experimental grey water reuse for subsurface irrigation

(Brittain and Karpiscak, 1989)

Indoor:

1. 4 litres-per-flush toilets using municipal water (if any)

2. $\quad 11$ litres-per-minute or less low flow showerheads

3. 6 litres -per-minute or less faucet aerators

4. hot water loop

5. sewer discharge limited to toilet, kitchen sink, and dishwasher

(Brittain and Karpiscak, 1989)

There are also several choices of reducing energy consumption of desert house and to shift its peak of energy demand, which are:

Thermal mass; Landscaping, porches, and outdoor living spaces adjacent to the home to provide optimum shade for the structure and maximum outdoor living area; High efficiency heat pump; In-line solar hot water preheated; Hot water supply loop to all faucets; Hot water tank and pipe insulation; Cost-effective and energy efficient appliances; Double-glazed windows/doors; Sun screens; Orientation; Appropriately sized windows and skylights for day lighting and passive solar gain in winter; Vented roof; Insulation (Brittain and Karpiscak, 1989).

For traditional desert houses, we also suggest a delighting strategy. In hot and dry land, the use of windows is not sufficient because it often produce local heating and illumination within the space. One of the better solutions for day lighting problems is the use of skylights.

Figure V

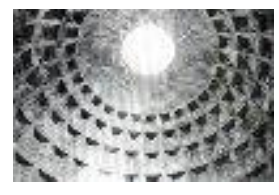

Skylights

Available at http://ag.arizona.edu/OALS/ALN/aln28/hampton.html
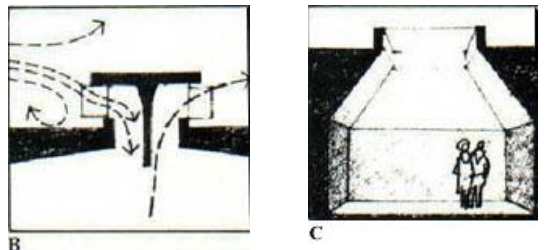

But actually, to allow penetration of daylight, whether through windows or skylights, into a building interior requires an architect or lighting designer to evaluate two essential components, which are thermal and luminous. Mistakes in measuring the perspective and intensity of the incoming sunlight would produce overheating, visual discomfort, deterioration of furnishings and the danger of solar radiation (Hampton, 1989).

In addition, there is also special consideration for rural homes. In Rural Areas the use of alternative energy source is more important than urban areas important. Lanoie (2005) provides alternatives of energy sources:
1. Solar Hot Water System
2. Solar House Design
3. Wood and Corn Stoves
4. Heating with Wood

\section{Bibliography}

[1]. Brittain, Richard G. \& Karpiscak, Martin M. 1989, 'Desert house: Water and Energy Conservation in the Sonoran Desert', [Online] Available at: http://ag.arizona.edu/OALS/ALN/aln28/brittain.html

[2]. 'Energywise House', 2005, [Online] Aobvila, Available http://www.bobvila.com/ArticleLibrary/Subject/Special_Features/EnergyWise_House/eHouse.html

[3]. Greenspun, Philip. 2004, 'House Design Ideas', Materialism, [Online] Available at http://philip.greenspun.com/materialism/housedesign/ 
[4]. Hampton, Warren R. 1989, 'Day lighting Strategies: Sky lighting in Hot Dry Climates', [Online] Available at http://ag.arizona.edu/OALS/ALN/aln28/hampton.html

[5]. Katuin, Ken. 2005, 'How Much Will It Cause to Build Your New Home?', About, [Online] Available at http://architecture.about.com/cs/buildyourhouse/a/costs.htm

[6]. Lanoie, Russel H. 2005, 'Alternative Energy', Rural Home Technology

[7]. Prudden, Joe, 'Desert Organic Design', Dream green Homes, [Online] Available at http://www.dreamgreenhomes.com/plans/desertorganic.htm

[8]. Solieman, Khalifa A. \& Clark, Kenneth N. 1989, 'Characteristic Urban Features of the M'zab Valley Communities of Algeria', [Online] Available at http://ag.arizona.edu/OALS/ALN/aln28/solieman.html

[9]. 'Sustainable Housing Design Guide', [Online] Available at http://www.archive2.officialdocuments.co.uk/document/deps/cs/shdg/ch04/

[10]. 'The Right Design', 2004, Irish Farmers Journal, [Online] Available http://www.farmersjournal.ie/house_planning_2004/rightdesign.pdf\#search='rural\%20house\%20design' 